\title{
¿Reconversión inconclusa o régimen de acumulación dual? Una lectura regulacionista de las transformaciones recientes en el sector vitivinícola argentino
}

\section{Juan Ignacio Staricco}

Universidad Nacional de Córdoba Facultad de Ciencias Económicas - CONICET.

Centro de Investigaciones en Ciencias Económicas - Grupo Vinculado (CIECS), Argentina staricco.juan@gmail.com

Cita sugerida: Staricco, J. I. (2018). ¿Reconversión inconclusa o régimen de acumulación dual? Una lectura regulacionista de las transformaciones recientes en el sector vitivinícola argentino. Mundo Agrario, 19(41), e088. https://doi.org/10.24215/15155994e088

Recibido: 28 de Junio 2017 - Aceptado: 27 de Marzo 2018 - Publicado: 15 de Agosto 2018

(c) (1) (-) (2) Esta obra está bajo licencia Creative Commons Atribución-NoComercial-CompartirIgual 4.0 Internacional http://creativecommons.org/licenses/by-nc-sa/4.0/deed.es_AR 


\section{¿Reconversión inconclusa o régimen de acumulación dual? Una lectura regulacionista de las transformaciones recientes en el sector vitivinícola argentino}

Unfinished reconversion or dual regime of accumulation? A regulationist reading of the recent transformations in the Argentinean wine sector

Juan Ignacio Staricco

Centro de Investigaciones en Ciencias Económicas -Grupo Vinculado CIECS-CONICET,

Instituto de Administración (Facultad de Ciencias Económicas, Universidad Nacional de Córdoba),

Argentina

staricco.juan@gmail.com

\section{Resumen:}

Este artículo ofrece un análisis de las transformaciones experimentadas por el sector vitivinícola argentino durante los últimos treinta años. Para ello, se recurre a un marco conceptual inspirado en la Teoría de la Regulación y los debates contemporáneos en torno a su aplicación en análisis sectoriales. Utilizando datos estadísticos y literatura académica como fuentes, el artículo analiza el devenir del régimen de acumulación y el modo de regulación del sector vitivinícola. La principal conclusión ofrecida es que es más preciso caracterizar la situación actual de la industria por la existencia de un régimen de acumulación dual y no por una "reconversión inconclusa"

Palabras Clave: Teoría de la regulación, Sector vitivinícola, Vino, Régimen de acumulación, Modo de regulación, Argentina.

\section{Abstract:}

This article offers an analysis of the main transformations experienced by the Argentinean wine sector during the last three decades. To do so, it resorts to a conceptual framework inspired by Regulation Theory and the contemporary debates on its sectorial applications. Using statistical data and academic literature, the article analyzes the historical evolution of the wine sector's regime of accumulation and mode of regulation. It is concluded that it is more accurate to characterize the industry's current situation by the existence of a dual regime of accumulation and not an "unfinished reconversion"

KEYWORDS: Regulation Theory, Wine sector, Wine, Regime of accumulation, Mode of regulation.

\section{INTRODUCCIÓN}

La industria vitivinícola argentina ha experimentado importantes transformaciones en las últimas tres décadas. Ha pasado de una profunda y larga crisis, que se extendió durante los setenta y ochenta, a convertirse en un foco de inversiones durante los noventa y adquirir un importante dinamismo exportador desde principios de siglo. Habitualmente, este proceso suele ser conceptualizado a través de la noción de reconversión, que da cuenta del paso de una estructura productiva tradicional a una nueva. Si bien parte de la literatura que analiza la reconversión del sector vitivinícola lo hace con tono celebratorio, postulándola como uno de los casos más exitosos de la historia reciente, la mayor parte ha desarrollado una perspectiva crítica, en la que se destacan la heterogeneidad y desigualdad con las que este proceso ha beneficiado a los actores sectoriales.

Dentro de este último grupo destaca una corriente que hace énfasis en el carácter "incompleto" o "inconcluso" del proceso de reconversión. Así, los trabajos de Azpiazu y Basualdo (2001, p. 192; 2003, p. 3), quizás las más detalladas descripciones del proceso durante los noventa, califican a la reconversión como "inconclusa, heterogénea y desigual", ya que los nuevos imperativos productivos y organizacionales no han terminado de reemplazar a los anteriores ni han sido apropiadas por la totalidad de los actores. En esta misma línea, Altschuler (2012, p. 159) argumenta que a causa de una reconversión "heterogénea, incompleta y desigual" el sector vitivinícola se encuentra atravesado por dos modelos tecnológicos y socioproductivos 
diferentes. Haciendo hincapié en la desigualdad con la que se ha expresado, Hernández Duarte (2014, p. 5) esgrime que la reconversión representa un "complejo e inconcluso proceso de reestructuración que vulnerabilizó a ciertos sectores, [y] potenció a otros".

En este artículo argumentaré que, si bien esta corriente de la literatura destaca acertadamente las desigualdades y relaciones de poder provocadas por el proceso de reconversión, caracterizar a este fenómeno como incompleto o inconcluso es cuanto menos impreciso. El principal problema radica en que esos calificativos se hallan impregnados con una suposición teleológica: si se afirma que la reconversión no ha sido completada o concluida es porque se la supone como el horizonte último hacia el que avanza la industria como un todo. Así, dichas descripciones asumen implícitamente el carácter transitorio de la heterogeneidad y desigualdad, las que se verían reducidas o eliminadas cuando el proceso de reconversión finalizase.

Si bien estos trabajos de investigación ofrecen precisas y reveladoras descripciones de procesos empíricos, la falta de un marco conceptual capaz de dar cuenta con mayor precisión de las características estructurales del sector termina haciéndolos incurrir en supuestos teleológicos. Es por ello que aquí propongo la utilización de una perspectiva analítica basada en la Teoría de la Regulación para analizar el devenir histórico reciente de la industria vitivinícola, demostrando así que la dualidad característica del sector es un rasgo estructural de su régimen de acumulación y no un estado transitorio producto de un proceso de transformación inconcluso.

Este artículo comienza con una presentación de los principales conceptos de la Teoría de la Regulación y una discusión sobre el modo en que esta perspectiva puede ser adaptada para aplicarla en el análisis del sector agroalimentario. A continuación, se describe la evolución reciente del régimen de acumulación y el modo de regulación de la industria vitivinícola argentina, y se demuestra que la refundación del sector está basada en una dualidad estructural. Dado el carácter histórico de esta perspectiva, buena parte del análisis empírico toma como referencia a la región más tradicional del sector, Mendoza, y la complementa con referencias a otras regiones o a la industria como un todo cada vez que fuere relevante. Por último, en las conclusiones se reflexiona acerca de las implicaciones tanto empíricas como teóricas de este análisis.

\section{Teoría de la Regulación (TR): una Perspectiva SEctorial}

La TR parte del supuesto de que la realidad social se halla constituida por relaciones sociales contradictorias, y hace de su institucionalización, crisis y cambio su objeto de estudio (Neffa, 1998, pp. 45-6). Así, postula que la acumulación estable y continuada constituye una excepción a la regla, ya que se vuelve posible sólo cuando la lucha que es inherente a las relaciones sociales contradictorias puede ser canalizada de manera tal que se vuelva compatible con un proceso de acumulación regular. Es por ello que desde sus orígenes el objetivo de la TR ha sido comprender esos raros momentos de estabilidad. Estos supuestos subyacen a los principales conceptos de la TR, que serán presentados a continuación.

La noción de régimen de acumulación describe una situación macroeconómica de largo plazo en la que las transformaciones en las condiciones de producción y consumo evolucionan en paralelo, manteniendo un patrón complementario (Lipietz, 1983, p. xvi). Los regímenes de acumulación estabilizados son el resultado de "los efectos coercitivos específicos de formas institucionales que logran crear una coherencia entre las estrategias y expectativas de los agentes que habitan una economía de mercado capitalista" (Lipietz, 1988, p. 32). La clave, entonces, radica en el surgimiento de un modo de regulación compatible, que se define como una combinación relativamente coherente de formas institucionales o estructurales con la capacidad de ajustar, guiar o coaccionar la conducta individual y colectiva de manera tal que el régimen de acumulación se estabilice (Boyer y Saillard, 2002, p. 64; Lipietz, 1983, pp. xvi-xvii). Cuando un régimen de acumulación se combina exitosamente con un modo de regulación, nos hallamos en presencia de un modo de desarrollo (Boyer y Saillard, 2002:64).

Un modo de regulación se encuentra constituido por un grupo relativamente coherente de formas institucionales o estructurales, que se entienden como la configuración o codificación específica que las 
relaciones sociales fundamentales asumen en un determinado momento histórico y área geográfica (Neffa, 2006, p. 186). Las relaciones de producción e intercambio típicas del capitalismo se vuelven posibles y son normalizadas a través de tres formas institucionales: la relación salarial, la moneda y la competencia. Estas tres formas institucionales expresan, respectivamente, el modo en que la plusvalía es apropiada, cómo las unidades económicas se interconectan y el patrón a través del cual se relacionan los distintos centros de acumulación (Boyer, 1990a, p. 37). Otras dos formas institucionales son también relevantes -el Estado y el modo de inserción en el contexto internacional-, completando así el quinteto de formas institucionales que constituye el núcleo de la TR (Neffa, 1998; 2006).

Asimismo, la TR trabaja con dos nociones principales de crisis: las crisis cíclicas o menores (Boyer y Saillard, 2002, p. 65) ocurren cuando la producción y acumulación de plusvalía es interrumpida temporalmente pero su restablecimiento puede lograrse en el marco de las formas institucionales imperantes, por lo que Lipietz (1987, p. 34) las llama crisis dentro de la regulación. Las crisis estructurales o mayores, en cambio, ocurren cuando el modo de regulación y el régimen de acumulación se vuelven incompatibles, por lo que Lipietz las describe como crisis de la regulación.

La TR fue desarrollada originalmente con el objetivo de dar cuenta de fenómenos macroeconómicos. Sin embargo, la posibilidad de realizar una lectura regulacionista de la historia reciente de la industria vitivinícola argentina exige adoptar una perspectiva sectorial. Así, se nos plantea un desafío: ¿cómo adaptar la formulación original de la TR para poder dar cuenta del nivel sectorial (agrícola)?

Bartoli y Boulet (1990) ofrecieron una contribución pionera al establecimiento del nivel sectorial como una escala de regulación en sí misma. Su objetivo fue encontrar un camino intermedio entre los dos riesgos que identificaron en la literatura: por un lado, la posibilidad de una transposición mecánica de un nivel al otro, ya que una perspectiva así identificaría un modo de regulación global ${ }^{1}$ que se impondría a los diferentes sectores, los cuales simplemente reproducirían el patrón general. Por otro lado, existe el riesgo opuesto, que es considerar a los sectores como el nivel de regulación primario, asumiendo que los regímenes de acumulación y las formas estructurales sectoriales se originan y adquieren coherencia exclusivamente en ese nivel. Una perspectiva así no podría dar cuenta de los condicionamientos impuestos por los imperativos más generales de acumulación o reproducción social (Bartoli y Boulet, 1990, p. 18). Por lo tanto, Bartoli y Boulet proponen comenzar el análisis con la hipótesis de la existencia de un nivel de regulación sectorial específico, pero dejando para el análisis empírico, caso por caso, la caracterización del modo en que éste se articula con el nivel global.

De manera similar, Boyer (1990b) ha descripto cuatro maneras en las que los modos sectoriales de regulación pueden ser analizados. Primero, a partir de la proyección del nivel global en el nivel sectorial. Esto significaría que los cambios en la agricultura durante los años sesenta habrían sido el resultado de la adopción de la lógica y formas estructurales características del fordismo, lo que evidencia una correspondencia entre los modos de regulación sectorial y global. Segundo, algunos investigadores han sabido reconocer las especificidades del sector agrícola, pero las han explicado desde un punto de vista funcionalista, en términos de necesidades impuestas por los niveles globales de regulación y acumulación. Tercero, el camino inaugurado por Bartoli y Boulet ha conducido a la suposición de la existencia de regímenes institucionales específicos a nivel sectorial que disfrutan de una autonomía relativa con respecto al modo de desarrollo global. Mientras que Boyer critica a los primeros dos enfoques por su incapacidad para reconocer las especificidades sectoriales, encuentra que el tercero sobreestima la autonomía y originalidad del sector. Así, Boyer propone un enfoque al que denomina sintético, el cual considera que el modo de regulación sectorial, por ejemplo, surge de la articulación entre los dispositivos institucionales propios del sector y el modo de regulación global. Este enfoque aspira a superar la tensión inherente a la dicotomía macro/sector reconociendo a la agricultura como un sector específico pero no autónomo.

Este artículo se propone realizar una contribución a la perspectiva sintética propuesta por Boyer. Así, y a diferencia de varios autores regulacionistas (además de Bartoli y Boulet, 1990, ver, por ejemplo, Lacroix, Mollard y Bel, 1994, o Touzard, 1994), he decidido continuar utilizando los conceptos clásicos de la TR. 
Esto se debe a que no partiré de concebir, por ejemplo, al modo de regulación sectorial como una entidad en sí misma, sino que lo entenderé como el punto de encuentro entre un modo de regulación global y los elementos regulatorios específicos del sector. Esto significa, siguiendo a Boyer, que conceptualizaré al modo de regulación sectorial como una forma "específica" que adopta el modo de regulación global (cf. Staricco, 2016:4-5). Bartoli y Boulet (1990, p. 11) rechazaron enfáticamente la posibilidad de recurrir a las formas institucionales tradicionales para analizar un sector, aduciendo, por ejemplo, que la moneda se halla regulada por el Banco Central y el Estado, o que la relación salarial responde exclusivamente al modo de regulación global. Mientras que es cierto que las fuerzas sectoriales no determinan a las formas estructurales a nivel global, la institucionalización particular que ellas asuman a nivel meso revestirá en muchos casos una especificidad distintiva como producto de las características y regulaciones específicas del sector. Por lo tanto, las cinco formas estructurales de la TR son consideradas pertinentes para el análisis aquí propuesto.

Ahora, si bien he decidido trabajar con las cinco formas estructurales originales, también considero relevante incluir una sexta: la representación del producto (Staricco, 2016, p. 5). Un sector se conforma alrededor de un(os) producto(s) en particular. En consecuencia, la representación dominante de un producto constituye un elemento clave para delimitar los límites de un sector y comprender la manera en la cual las relaciones de producción, circulación y consumo se han articulado dentro del mismo (cf. Touzard, 1994, p. 298; Bartoli y Boulet, 1990). Esto significa que el proceso de sectorialización (Bartoli y Boulet, 1990, p. 12) no está exclusivamente dado por la existencia objetiva de una división del trabajo, sino que también interviene una disputa en torno a la definición del producto que lo caracteriza y los medios para lograrlo. La representación del producto, por lo tanto, se convierte en una institución fundamental al analizar sectores económicos y es por ello que será considerada como una sexta forma institucional junto a la relación salarial, la competencia, la moneda, el Estado y el modo de inserción internacional.

\section{Dos modos DE DESARRollo DE LA ECONOMÍA ARGENTINA}

Luego de haber definido a los modos de regulación y regímenes de acumulación sectoriales como el resultado de la interacción entre fuerzas y estructuras globales y sectoriales, se vuelve indispensable comenzar el análisis con una breve descripción de las principales transformaciones que ha experimentado el modo de desarrollo de Argentina. Para dar cuenta de los cambios recientes más importantes en la industria vitivinícola es necesario introducir dos modos de desarrollo: primero, uno que tuvo lugar entre 1989 y 2002, y, segundo, uno que emerge en 2002 y se mantiene hasta el final del período abarcado por este trabajo 2. Como la realización de un análisis original de estos modos de desarrollo excede ampliamente el objetivo de este artículo, su descripción seguirá, en líneas generales, al trabajo de Neffa y Panigo (2010), quienes han analizado su evolución desde una perspectiva regulacionista.

El modo de desarrollo estructurado entre 1989 y 2002 se caracterizó por un modo de regulación competitivo, basado en la convertibilidad monetaria, y un régimen de acumulación parcialmente intensivo, con predominio del capital extranjero y sin consumo masivo (Neffa y Panigo, 2010). Como se esperaba que el crecimiento del PBI fuera obra del sector privado, el principal objetivo de este modo de desarrollo fue detener la caída (y eventualmente incrementar) la tasa de ganancia de las empresas privadas para incentivar la inversión. Así, una importante estrategia fue la flexibilización de la organización de las compañías, la producción y el trabajo. Un claro ejemplo de esto fue la reforma laboral, que estableció modos más flexibles para contratar trabajadores, redujo costos asociados a los salarios directos e indirectos y promovió la descentralización de las negociaciones colectivas.

La hiperinflación de finales de los ochenta fue resuelta con la ley de convertibilidad de 1991, que estableció un tipo de cambio fijo (1:1) entre el peso y el dólar. Se esperaba compensar el previsible déficit en la balanza comercial producido por la alta cotización del peso con la atracción de inversión extranjera directa. Es por ello que el gobierno eliminó los controles a los flujos de capitales y garantizó un tratamiento no discriminatorio 
a los de origen extranjero. La desregulación, sin embargo, no se limitó sólo a eso, sino que fue el principio rector en la relación entre el Estado y la economía.

A finales de los noventa este modo de desarrollo comenzó a demostrar su agotamiento, y evidenció no sólo su inhabilidad para producir crecimiento, sino también que su aplicación estaba produciendo una delicada situación social. Este explosivo contexto socioeconómico llevó a la crisis de 2001/02, señalando así el fin del modo de desarrollo.

La periodización de Neffa y Panigo (2010) señala a 2002 como el momento en que el modo de desarrollo en crisis comienza a ser reemplazado por un modo de regulación administrado -caracterizado por la determinación de los salarios a través de negociación colectiva y el crecimiento de la inversión estatal- y un régimen de acumulación extensivo -basado en la expansión de la frontera agrícola y cambios menores en los procesos productivos-. Este período se encuentra marcado por la devaluación de 2002, que reemplazó a la convertibilidad por un sistema de flotación administrada, altas tasas de crecimiento del PBI hasta 2011 con excepción de 2009- motorizadas por la exportación de productos primarios poco elaborados y algunas manufacturas industriales y un aumento en la producción de bienes intermedios y de consumo, lo que trajo aparejado un considerable incremento del empleo pero sin fuertes subidas salariales. Su principal dificultad sería que la inflación, si bien controlada durante los primeros años, comenzaría a crecer más aceleradamente que la productividad.

Este nuevo período vino a rectificar muchas de las políticas de los noventa. El Estado intervino activamente con el objetivo de mantener un tipo de cambio competitivo que promoviera las exportaciones e hiciera las importaciones más caras. Asimismo, el Estado reestableció controles sobre los flujos de capital, renacionalizó varias empresas privatizadas y desarrolló una política fiscal expansiva con el fin de proveer subsidios y transferencias monetarias a sectores marginados, para promover así el consumo a través del aumento de los salarios indirectos.

Es importante destacar que, si bien el período 2001/02 señaló la crisis última de un modo de desarrollo y el surgimiento de otro -a partir de un quiebre con importantes características del anterior-, a nivel del sector vitivinícola sólo contribuyó a la profundización de la transición hacia una nueva estructura que ya había comenzado durante los noventa. Este fenómeno será analizado en las próximas dos secciones.

\section{El RÉGIMEN DE ACUMULACIÓN DE LA INDUSTRIA VITIVINÍCOLA}

Argentina ha sido históricamente uno de los principales productores mundiales de vino y es actualmente el quinto, detrás de Francia, Italia, España y Estados Unidos (OIV, 2016). Mientras que también ha sido tradicionalmente un país con altos niveles de consumo, las últimas tres décadas han atestiguado un descenso significativo. Esto ha resultado en un importante incremento en la brecha entre producción y consumo (de un $11 \%$ en el período 1986-1990 a un $37 \%$ en 2011), lo que llevó a la Organización Internacional de la Viña y el Vino (OIV, por sus iniciales en francés) a cambiar la clasificación de Argentina de país consumidor a exportador neto (OIV, 2009). La Figura 1 muestra como desde 1977 la evolución de la demanda ha sido negativa, lo que arrastró hacia abajo también los niveles de producción. 


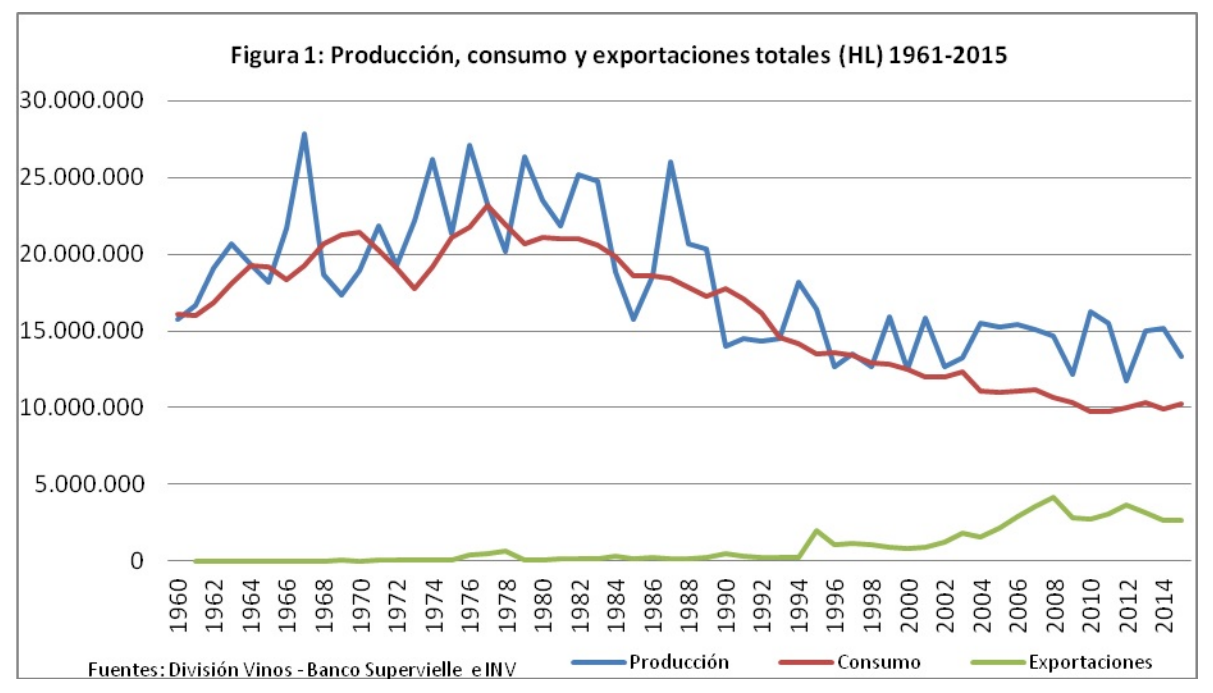

Esto fue acompañado por un cambio paradigmático del sector, que comenzó a producir vinos finos para el mercado internacional. Mientras que, como se puede apreciar en la Figura 1, las exportaciones habían sido insignificantes antes de 1995, ahora se han convertido en una alternativa fundamental ante el menguante consumo local. Esta transformación ha dividido al régimen de acumulación de la industria en dos: un sector reconvertido, creciente y en expansión, que produce vinos de alta calidad principalmente para el mercado internacional, y uno tradicional y en contracción, que produce vinos de mesa para el mercado interno.

El régimen de acumulación basado en la cantidad

Durante la mayor parte de su historia, la industria vitivinícola local se estructuró en torno a un modelo productivista (Azpiazu y Basualdo, 2001; Bocco et al, 2007; Bocco y Dubbini, 2007), que se basaba en la elaboración de vino de mesa para consumo local masivo. Conocido como el modelo centenario (Mateu y Stein, 2008; Mateu, 2007), sus orígenes datan de las últimas décadas del siglo XIX, cuando el creciente número de inmigrantes italianos y españoles que llegaron al país trajeron consigo el conocimiento necesario para la producción de vino y conformaron un importante mercado local para el producto. El constante crecimiento del consumo fue una de las características distintivas: salta de los 23 litros per cápita en 1880 a los 62,2 en 1914 (Mateu, 2008, p. 26). Mientras que el siglo XX atestiguaría cambios en el nivel de consumo como consecuencia de variaciones en los precios y el poder adquisitivo de los salarios, la tendencia dominante continuó siendo la del crecimiento, el cual llegó a su apogeo en 1970, con un promedio de 92 litros per cápita (Stein, 2008, p. 41).

El principal objetivo de la industria era producir grandes cantidades de vino de mesa para satisfacer una demanda nacional homogénea y poco diferenciada. La concepción dominante del producto entendía al vino como una mercancía a ser producida masivamente por su importancia como bien-salario. Un claro ejemplo de cómo funcionaba esta lógica es el que da Stein (2008, pp. 38-9) cuando describe cómo entre 1943 y 1973 la superficie total implantada utilizada para la producción de vino pasó de 150.000 hectáreas a 330.000, pero la producción total de vino creció de 9.000.000 de hectolitros a 28.000.000. Esto significa que los aumentos de producción no sólo se conseguían a través de la expansión de viñedos, sino también con el incremento de sus rendimientos. La principal estrategia era implantar variedades más productivas, lo que se hizo ampliamente durante los sesenta y setenta. La variedad conocida como "criolla" - de bajo potencial enológico- se convirtió en la dominante por su alto rendimiento: seis veces mayor que su competidora más cercana, la pedro ximénez -otra variedad de bajo potencial-, y 15 veces mayor que una uva de alto potencial como la malbec. A principios de los setenta la industria vitivinícola local podía describirse a sí misma como la campeona del paradigma de la cantidad, ya que Argentina se había convertido en el país del mundo con el más alto nivel de producción de vino por hectárea (Costa, 1972, p. 16). 
Los desarrollos tecnológicos eran puestos al servicio de esta concepción del producto, ya que la mayoría aspiraban a aumentar los rendimientos de las viñas y la capacidad de las bodegas para procesar uvas, como así también acelerar los tiempos de vinificación (Stein, 2008, p. 34). En esta industria orientada hacia adentro las exportaciones a países vecinos tenían un rol marginal y el acceso a mercados distantes era relegado a oportunidades esporádicas (Azpiazu y Basualdo, 2003, p. 13).

A pesar de su larga historia, la industria vitivinícola nunca se caracterizó por su estabilidad. A través de los años ha sido víctima de múltiples crisis cíclicas de sobreproducción y ha requerido de una activa intervención estatal con el fin de superar los períodos más álgidos (Mateu, 2008, p. 29). Sin embargo, y a pesar de que las depresiones no eran inusuales (ver Tacchinni, 2008; Mateu, 2007), la crisis que se desenvolvió entre los años setenta y 1990 terminó convirtiéndose en un momento bisagra. Durante estas dos décadas la industria no sólo se vio enfrentada a la situación usual de sobreoferta, sino que el problema se vio empeorado por un nivel de demanda local en constante disminución. El consumo se contrajo de 88,45 litros per cápita en 1977 a 53,67 en 1989, su nivel más bajo en 30 años (ver Figura 1). Mientras que los cambios en el nivel de consumo no habían sido ajenos a la industria, la contracción que comenzó en los setenta fue diferente en dos aspectos. Primero, porque representó un nuevo patrón: hasta ese momento los cambios en el consumo habían obedecido a cambios en el poder de compra de los salarios, pero a partir de ahora comenzaban a reflejar una transformación en el gusto de los consumidores (Staricco, 2015, p. 149). Segundo, la disminución del consumo, que comienza en los setenta, no tiene precedentes por su constante caída. Mientras que la lógica de la industria había sido siempre la de expandir la oferta sobre la base de la expectativa de una demanda en constante aumento, este descenso sostenido vino a alterar el supuesto básico que atravesó al régimen de acumulación desde sus inicios.

Numerosas medidas fueron tomadas por el Estado (nacional y provincial) con el fin de estabilizar el sector, tanto de manera directa -control de precios, prohibición de plantar nuevas viñas, compra de vino para eliminarlo del mercado o destilarlo, compra de uvas a pequeños productores por parte de bodegas estatales- como indirecta, a través de las regulaciones establecidas por el principal órgano del sector, el Instituto Nacional de Vitivinicultura (INV) - el establecimiento de cuotas de producción y comercialización de vino a nivel nacional, regional e individual o la prohibición de vinificar ciertos porcentajes de la producción de uvas, entre otras-. A pesar de la activa intervención gubernamental, la crisis -con sus propios orígenes sectoriales potenciados por un contexto macroeconómico de alta inflación y crecimiento negativo- llevó a la erradicación de enormes cantidades de viñedos y bodegas.

La crisis que comenzó en los setenta terminó siendo intratable, ya que ninguna de las políticas que habían sido exitosas en ocasiones anteriores pudo iniciar un proceso de recuperación. Mientras que las crisis precedentes pueden ser entendidas como crisis "dentro de la regulación" (desequilibrios cíclicos que podían ser corregidos en el marco de las formas estructurales imperantes), la que alcanzó su clímax durante los ochenta debe ser descripta como una crisis "de la regulación": un cambio importante en uno de los pilares del régimen de acumulación (la caída sostenida del consumo) volvió obsoleto al modo de regulación e hizo necesaria la transformación de sus formas estructurales para poder restablecer la acumulación. Además, a medida que la crisis sectorial se potencia, también lo hace la del modo de desarrollo nacional, lo que contribuye con su desestabilización. De esta manera, la crisis del régimen de acumulación basado en la cantidad coincide con la crisis del modo de desarrollo de la época; y no se producirá la renovación del régimen de acumulación sectorial sino hasta que emerja un nuevo modo de desarrollo (ver Figura 2). 


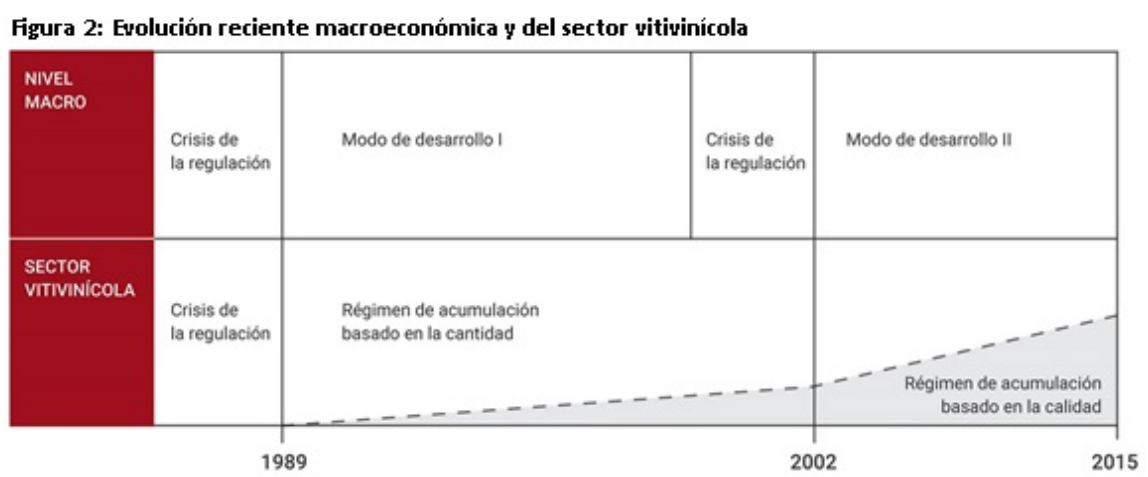

A partir de los setenta comenzaron a ocurrir importantes cambios a nivel global (Artopoulos, Friel y Hallak, 2010, pp. 74-84). Países con niveles históricamente altos de consumo (como Francia, Italia o España) comenzaron a experimentar tendencias a la baja, mientras que en algunos mercados no tradicionales (como Estados Unidos, Reino Unido o Rusia) el consumo comenzó a crecer. Este fenómeno trajo consigo un cambio en las preferencias. Mientras que en el pasado el marcado internacional de vinos estuvo dominado por los llamados productores del viejo mundo (Francia, Italia, España y Portugal), una tendencia comenzó a emerger -especialmente entre los consumidores nuevos- en favor de vinos más frutales y frescos, precisamente aquellos que los productores del nuevo mundo (Estados Unidos, Australia, Chile, Argentina, Sudáfrica y Nueva Zelanda) podían ofrecer. si comparamos los períodos 1990-94 y 2005-09, los países del nuevo mundo pasaron de producir el $18,2 \%$ del vino total al $26,7 \%$, y, en cuanto a las exportaciones, avanzaron de un 6,4 \% en términos de valor y un $7 \%$ en términos de volumen a un 23,1 \% y 29,3\% del total mundial respectivamente (Staricco, 2015, p. 152). Así, un nuevo contexto internacional comenzó a emerger, en el que la supremacía de los productores del viejo mundo comenzó a ser disputada por productores no tradicionales y el comercio internacional se acrecentó (Bocco et al, 2007, p. 49).

Mientras que Argentina experimentaba una caída en los niveles de consumo desde los setenta, a partir de los noventa comenzó a volverse evidente también un cambio en la estructura de la demanda local. Así, si se compara el consumo de vinos de mayor calidad (varietales y espumantes) con el de vinos básicos, se verá que los primeros pasaron de representar un $10 \%$ del total en 2004 (primer año en que INV registra la estadística) a un $26 \%$ en 2015 , mientras que si se analiza por segmentos de precio se puede ver que el consumo combinado de vinos de mediano y alto precio supera a los de bajo precio desde 2009 (Staricco, 2015, pp. 153-4). Así, es posible afirmar que la caída del consumo local vino acompañada de un cambio en la estructura de la demanda, con los vinos finos creciendo a expensas de los de mesa.

Los cambios de la época tanto a nivel local como internacional les ofrecieron a los productores argentinos la posibilidad de seguir el camino de los países del nuevo mundo como una forma de inserción en el mercado global. Pero hacerlo implicaría un importante proceso de reconversión: era necesario pasar de la tradicional producción de vino de mesa para consumo masivo en el mercado local a la producción de vinos finos acordes al paladar de los consumidores foráneos.

En el corazón de este proceso de reconversión se encontraba una nueva representación del producto (Heredia, 2015, p. 269). Si hasta el momento el éxito de la acumulación había estado determinado por parámetros cuantitativos, la transición hacia los vinos finos demandaba el establecimiento de nuevos parámetros determinados por la idea de calidad. Como consecuencia, las ganancias no estarían asociadas exclusivamente al aumento en el volumen de ventas, sino al incremento de la calidad y el valor de cada unidad individual. Así, una parte de la industria comenzaría a desplazar sus actividades de la producción de vinos de mesa a la producción de vinos finos apostando por una diversidad de productos con características distintivas y procesos de elaboración específicos. 
Mientras que esta nueva perspectiva había comenzado a ser considerada seriamente en los ochenta, la situación macroeconómica no ofrecía las condiciones necesarias para las importantes inversiones que tal reconversión requería. No sería sino hasta los noventa, cuando cambios sustanciales en el modo de desarrollo nacional tuvieron lugar, que este sector comenzaría su transformación. Favorecida por la eliminación de impuestos a las transacciones bursátiles, la ausencia de controles a los movimientos de capital y la posibilidad de obtener ganancias en dólares, la reconversión de la industria vitivinícola fue promovida pioneramente por capitales foráneos, quienes fueron luego seguidos por grandes grupos nacionales, fondos de inversión y algunas familias tradicionales (Chazarreta, 2013; Heredia y Poblete, 2013). La mayoría de los nuevos jugadores que ingresaron a la industria vitivinícola argentina eran subsidiarios de grupos internacionales que contaban con la experiencia de haber reconvertido sus operaciones en otros países y ya se encontraban posicionados en el mercado internacional (Azpiazu y Basualdo, 2003).

El nuevo contexto macroeconómico -y en especial la apreciación del peso- posibilitaron la importación de las tecnologías necesarias para materializar la nueva representación del producto en técnicas y procesos concretos (cf. Maclaine Pont y Thomas, 2012, p. 630). Los productores del nuevo mundo se distinguieron por el enfoque científico que adoptaron en la producción de uvas y vino. Este enfoque promovió una alta racionalización y desarrollo tecnológico de las prácticas agrícolas (Maclaine Pont y Thomas, 2012) que supusieron importantes desafíos para los productores tradicionales, no sólo desde el punto de vista de las inversiones requeridas, sino también con respecto a la lógica de trabajo. Un buen vino sólo puede ser producido con uvas de alta calidad, y la calidad de las uvas es inversamente proporcional a su cantidad, lo que demanda viñas con rendimientos muy bajos en comparación a las que utilizaron históricamente los productores locales. Los viñateros argentinos se verían obligados, entonces, a adoptar las innovaciones científicas y tecnológicas promovidas por el paradigma del nuevo mundo con el objetivo de controlar los rendimientos de sus plantaciones. Después de vidas completas trabajando de una misma manera muchos enfrentaron la necesidad de realizar grandes transformaciones para volverse parte del régimen de acumulación emergente.

A nivel agrícola, un proceso de "purificación varietal" (Maclaine Pont y Thomas, 2012, p. 633) tuvo lugar. La reconversión de los viñedos no sólo implicó una nueva manera de trabajar, sino también el reemplazo de las variedades de uvas históricamente utilizadas para la elaboración de vinos de mesa por variedades de alto potencial enológico. A partir de una muestra integrada por las 13 variedades de uvas más preponderantes en el año 2012 (que representaban un $86 \%$ del total de la superficie implantada), es posible observar que entre el año 1990 y 2012 la superficie destinada a variedades de alto potencial enológico crece un 157,82 $\%$, mientras que la superficie ocupada por variedades de bajo potencial enológico se reduce en un 46,10\% (Staricco, 2015, p. 159).

$\mathrm{Al}$ mismo tiempo, el régimen de acumulación emergente ha alterado el modo en que se relacionan los niveles agrícola e industrial (Azpiazu y Basualdo, 2003, pp. 39-40; Maclaine Pont, 2011). La mayoría de las bodegas pioneras de la reconversión mostraron una tendencia a la integración vertical, y decidieron administrar sus propios viñedos. Esto es consecuencia de que el énfasis en la calidad exige gran atención al proceso de producción vitícola. Así, la posibilidad de manejar viñedos propios le permite a la bodega producir el tipo de uva exacto que sus enólogos requieren.

Sin embargo, a pesar de los beneficios de la integración vertical, esta modalidad representa un 34,40\% del total de las uvas utilizadas en la elaboración de vino (Staricco, 2015, p. 161). Esto se debe a que las bodegas, que buscaban diversificar los riesgos que vienen con la producción primaria, reducir la complejidad organizacional y administrativa y evitar los costos de oportunidad asociados con la inmovilización del capital, optan por limitar el número de viñedos propios (Artopoulos, Friel y Hallak, 2010, p. 85). Para la producción de vinos de alta calidad no se suelen comprar uvas en el mercado, ya que dicha opción no les permitiría a los bodegueros tener control alguno sobre su proceso de producción. La estrategia preferida, en cambio, es establecer relaciones de semicautividad con productores vitícolas (Azpiazu y Basualdo, 2003; Rofman y 
Collado, 2005). Se trata de productores independientes que manejan sus propios viñedos pero bajo estrecha supervisión de la bodega, que toma decisiones técnicas activamente, controla la evolución de las viñas y define tiempos y procesos.

La reconversión ha sido liderada por las bodegas, lo que hizo de ellas el principal actor de la cadena. Han pasado del proceso mecánico de convertir uvas en vino a tener un rol fundamental en la adaptación de la producción primaria (a través del establecimiento de sus propios viñedos o la cooperación con productores semicautivos) y en las áreas de comercialización local e internacional. Este liderazgo inicial de las bodegas produjo una brecha entre el sector primario (dominado por pequeños productores, baja productividad y pobre calidad) y el secundario (con compañías en proceso de internacionalización, creciente productividad e interés en la calidad) (Azpiazu y Basualdo, 2003, pp. 21-22). Así, esta brecha explica el predominio inicial de la integración vertical en el régimen de acumulación basado en la calidad, y su posterior complementación con el desarrollo de relaciones de semicautividad.

Sin embargo, la transferencia de conocimientos y recursos al sector primario se ha visto limitada a los productores que trabajan con las bodegas del régimen de acumulación basado en la calidad, lo que dejó fuera a una importante cantidad de productores vitícolas. Los últimos, que no accedieron a la reconversión, se dividen entre los que continúan integrados al régimen de acumulación basado en la cantidad y aquellos otros que abandonaron la actividad ante la imposibilidad de poder vivir de los estrechos márgenes que caracterizan a este régimen (Acosta y Vitale, 2010; Moscheni y Carrizo Muñoz, 2015). Esto produjo un proceso de concentración de la propiedad a expensas de la expulsión de pequeños productores (Staricco, 2015, p. 169).

El régimen de acumulación basado en la calidad emerge en el marco del modo de desarrollo que viene a dominar los años noventa. Sin embargo, mientras que los cambios ocurridos luego de 2002 marcaron la transformación del modo de desarrollo nacional, a nivel del sector vitivinícola sólo fortalecieron la transición hacia una nueva estructura sectorial que se encontraba en marcha. Mientras que estas dos etapas macroeconómicas evidenciaron importantes diferencias, a nivel sectorial tuvieron efectos complementarios: en los noventa, la convertibilidad cambiaria, la sobrevaluación del peso, la desregulación y la ausencia de controles sobre los flujos de capital proveyeron el contexto necesario para la recapitalización de la industria vitivinícola. Así, la mayor parte de las inversiones y el trabajo fundacional de la reconversión ocurrió durante los noventa, pero a pesar de que este régimen de acumulación se apoyaba en el aumento de las exportaciones, el tipo de cambio relativamente alto todavía hacía a los vinos argentinos poco competitivos internacionalmente. Es gracias a la devaluación y el establecimiento de un tipo de cambio competitivo -ocurridos en 2002- que la industria vitivinícola experimentó un gran crecimiento en sus exportaciones, tanto en términos de volumen como, especialmente, de valor (ver Figura 3). Así, a partir de la articulación con un nuevo modo de desarrollo, las inversiones producidas durante los noventa comienzan a generar retornos y las tasas de ganancia a crecer. La relación entre el sector vitivinícola argentino y la economía macro ha demostrado diferentes patrones durante el período analizado (ver Figura 2). Hacia fines de los ochenta una crisis de regulación en el modo de desarrollo nacional es acompañada por una crisis de regulación en el sector vitivinícola. Una década más tarde, sin embargo, nos encontramos con una situación diferente, en la que una crisis de regulación a nivel macroeconómico fomenta el reemplazo de un modo de desarrollo por otro, pero a nivel sectorial no se desata crisis alguna, sino que la transformación a nivel nacional viene a consolidar el desarrollo del sector. 


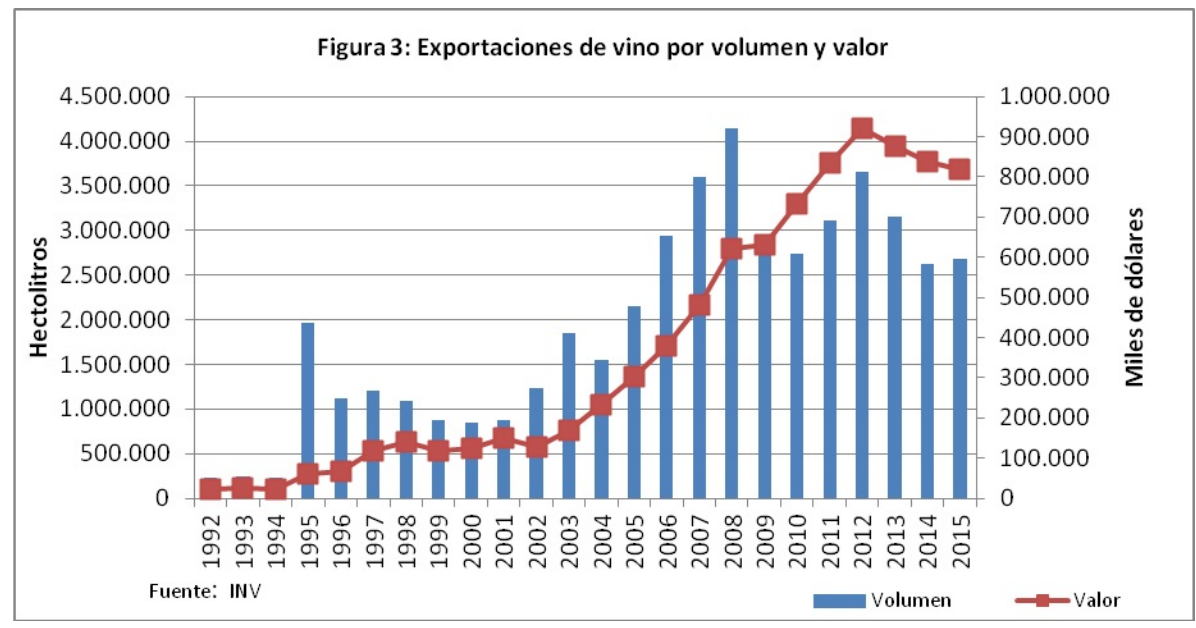

\section{EL MODO DE REgULACIÓN DE LA INDUSTRIA VITIVINÍCOLA}

Para poder comprender acabadamente las transformaciones recientes del régimen de acumulación sectorial, las condiciones bajo las cuales han sido posibles y los mecanismos que han facilitado su estructura dual, es importante examinar el modo de regulación del sector. Como se demostrará en esta sección, muchos de los cambios ocurridos en el modo de regulación han sido fundamentales para la transformación del régimen de acumulación sectorial. Asimismo, la complejidad derivada de la estructura dual de esta industria también se refleja en su modo de regulación, en el que algunas formas institucionales reproducen dicha dualidad mientras que otras evidencian perfiles mucho más homogéneos.

Relación salarial

Tradicionalmente, el tipo de trabajador dominante desde el siglo XIX ha sido el de los contratistas, quienes se encargan a lo largo del año de las diversas tareas que requiere el viñedo, recibiendo a cambio una casa en la propiedad, un modesto salario fijo y entre un $15 \%$ y $19 \%$ del total de la cosecha. En 1936 los contratistas trabajaban el $68 \%$ de la superficie cubierta por viñedos. Sin embargo, esta proporción se redujo a través del tiempo, hasta llegar al 43,3\% en 1979 y al 29,9\% al final de la crisis de los ochenta (Poblete, 2012, p. 522). Mientras que no existen datos contemporáneos sobre el número de contratistas, es un hecho que el surgimiento y prosperidad del régimen de acumulación basado en la calidad ha profundizado la tendencia hacia su desaparición y, más en general, ha promovido una amplia reorganización de relación salarial (Poblete, 2008; Heredia y Poblete, 2013).

El advenimiento del régimen de acumulación basado en la calidad implicó la adopción de nuevas tecnologías, principios científicos y técnicas, y tiempos de trabajo (Moscheni y Carrizo, 2015, pp. 330-5). Una consecuencia directa de estas transformaciones fue una nueva demanda laboral (Heredia, 2015, pp. 279-280). La introducción de nuevas tecnologías trajo consigo una modesta reducción en la cantidad de horas de trabajo por hectárea (Neiman y Bocco, 2001) pero, más importante, un cambio cualitativo en las habilidades esperadas de los trabajadores. Si bien el nuevo proceso de producción exige un mayor número de tareas (poda, desbrote, riego, atado, deshoje, cosecha), las mismas se realizan durante períodos relativamente cortos de tiempo, por lo que los administradores han preferido considerarlas como actividades atomizadas y contratar trabajadores ad hoc especializados en cada una de ellas (Neiman y Quaranta, 2016, pp. 91-3). Esta situación ha llevado a la desaparición de muchos de los puestos permanentes para trabajadores poco calificados (especialmente los contratistas) y a su reemplazo por puestos temporarios. En lo sucesivo, éste se convertiría en el patrón dominante en la producción vitícola, que para el año 2005 ya contaba con un $23 \%$ de trabajadores permanente y un $77 \%$ de trabajadores temporarios (Poblete, 2012, p. 527). 
Ésta, sin embargo, no sólo ha sido la premisa del sector, sino también la lógica del modo nacional de desarrollo que, durante los noventa, promovió el aumento de las tasas de ganancia a través de la flexibilización de las relaciones laborales. Las transformaciones en la relación salarial, por lo tanto, emergieron como resultado de, por un lado, los cambios en el proceso productivo y la estructura de la demanda laboral impulsados por el desarrollo del régimen de acumulación basado en la calidad y, por el otro, la promoción de la liberalización y flexibilización de las relaciones laborales por parte del modo global de regulación.

Así se volvió popular - y continúa siéndolo- la figura de trabajador autónomo. Debido a la tendencia hacia la reducción del número de trabajadores permanente poco calificados, muchos contratistas comenzaron a perder sus trabajos como tales, recibiendo a cambio la oferta de volver a ser contratados pero como monotributistas (Poblete, 2011, p. 46). Este fue un cambio desventajoso, ya que les implicó la pérdida de su hogar en la propiedad, dejar de percibir asignaciones familiares y tener que asumir directamente los tributos de los que antes se encargaba el patrón.

Otra estrategia en la misma dirección ha sido la de tercerizar la contratación de trabajadores (Neiman y Quaranta, 2016). Diferentes modos de organización, como las cuadrillas, agencias de empleo eventual (Fabio, 2010) o cooperativas de trabajo (Poblete, 2011) han sido y continúan siendo utilizadas por los empleadores con el objetivo de ahorrarse las contribuciones vinculadas a la relación de dependencia y transferir las tensiones inherentes a la relación salarial al proveedor de servicios.

Mientras que los años noventa atestiguaron un incremento en la flexibilidad de las condiciones de trabajo, el modo de desarrollo que surgió en los dos mil intentó remediar algunos de sus efectos. Sin embargo, tanto la revitalización de las negociaciones colectivas como el incremento en los beneficios sociales y los determinantes indirectos del salario alcanzados durante este período han tenido un impacto limitado, ya que constituyen medidas que benefician principalmente a los trabajadores en relación de dependencia. Como la relación salarial global ha dejado intactos importantes elementos destinados a flexibilizar las relaciones laborales, la situación de los trabajadores poco calificados continúa caracterizándose por la discontinuidad y la precariedad (Neiman y Quaranta, 2016).

Competencia

A nivel local, a pesar de la tendencia hacia un aumento en la calidad de los vinos demandados, el producto más relevante continúa siendo el vino de mesa. Junto con los vinos finos de menor precio ("selección") constituyen el segmento dominante, tanto en términos de volumen como de valor. Este segmento se caracteriza por su alta concentración, con sólo tres empresas fraccionando más del $60 \%$ de los vinos vendidos: FECOVITA (26,7 \%), Peñaflor (24\%) y RPB-Baggio (12\%) (Miranda, 2014). Esta concentración obedece al hecho de que el sector de los vinos de mesa se caracteriza por tener precios bajos y márgenes de ganancia reducidos, lo que hace necesario alcanzar economías de escala para permanecer en la competencia.

El alto nivel de concentración le otorga a estas tres empresas, por un lado, poder oligopsónico frente a los múltiples, y mayoritariamente pequeños, productores de uvas y bodegas trasladistas que caracterizan al régimen de acumulación basado en la cantidad, los cuales no tienen poder para influir en el proceso de formación de precios. Por el otro lado, dada la multiplicidad de compradores y la falta de competidores comparables, estos tres actores dominantes ejercen un poder oligopólico en la formación del precio del vino de mesa.

El segmento más alto de los vinos finos presenta, en cambio, un escenario mucho más competitivo en el que participan alrededor de unas 45 empresas (Bocco et al, 2007, p. 73). La competencia dentro del segmento se estructura en torno a varios niveles de calidad con diferentes jugadores participando dentro de cada uno de ellos y la diferenciación de productos ocupando un lugar central. El precio de las uvas dentro de este segmento no sólo es más alto, sino que también se encuentra sujeto a mayor negociación, ya que las características finales de la producción pueden aparejarles precios por encima o por debajo del promedio.

En el mercado internacional los productores argentinos no cuentan con poder alguno para definir los precios y deben adaptarse a los imperantes, que son el resultado de procesos de formación de precios 
competitivos. Como el mercado internacional es particularmente sensible a los cambios de precio, los jugadores disponen de poco margen para incurrir en aumentos. Por ello, el alza en los costos experimentado por las bodegas argentinas en los últimos años (ver: inserción internacional) ha hecho que redujeran sus envíos de vinos de menor valor se destinaran, en cambio, al mercado interno, donde sí pueden trasladar el aumento de costos a los precios. Esto ha hecho que el mercado local de vinos finos se vuelva aún más competitivo.

Es importante destacar que, si bien existen importantes diferencias entre los diversos mercados aludidos y entre ambos regímenes de acumulación, en la práctica existen actores (en especial bodegas grandes de capital nacional) que participan en más de un mercado y que adoptan prácticas de ambos regímenes, lo que les permite diversificar sus inversiones y distribuir el riesgo asociado a la especialización (Azpiazu y Basualdo, 2003; Artopoulos, Friel, y Hallak, 2010).

\section{Moneda}

Las transacciones en la industria vitivinícola argentina se caracterizan por un alto grado de informalidad, ya que los contratos no son habituales (Azpiazu y Basualdo, 2003, p. 40). Con frecuencia las bodegas compran uvas a sus proveedores habituales, pero no llegan a acuerdos sino hasta la cosecha, cuando es posible evaluar la calidad final del producto. Así, si bien en la práctica las relaciones entre las bodegas y sus proveedores suelen mantenerse en el tiempo, su carácter informal ofrece poca certeza a los últimos con respecto al volumen y precio final de la transacción.

Martín (2009, p. 86) describe cómo la nueva relevancia que el proceso de producción de las uvas adquiere con el surgimiento del régimen de acumulación basado en la calidad ha llevado a un modo de integración "híbrido", en el que una integración "total” (caracterizada por el monitoreo y control técnico permanente por parte de la bodega) se combina con una "informal" (dada la ausencia de acuerdos vinculantes), originando un "control técnico, económico y político por parte del eslabón industrial en detrimento de la capacidad de tomar decisiones de los productores".

El sistema de pagos en la industria vitivinícola varía de acuerdo a las relaciones establecidas entre diferentes actores y la calidad de sus productos. Sin embargo, puede decirse que en el caso de las uvas de menor calidad, la tendencia dominante es que las bodegas paguen a los productores en 12 cuotas mensuales a lo largo del año. En el caso de las uvas de alta calidad el panorama es más variado. Allí la tendencia es pagar en períodos más cortos de tiempo: en tres, seis o nueve cuotas de acuerdo con el tipo de relación entre el comprador y su proveedor, y la calidad del producto.

Después del default de 2002 las opciones internacionales de crédito se redujeron seriamente, por lo que las posibilidades se limitaron, principalmente, a fuentes locales. Las opciones privadas de crédito han sido una alternativa para las bodegas y productores más grandes, pero en el caso de los más pequeños (especialmente productores de uvas para vino de mesa), las condiciones han sido demasiado exigentes. El acceso al crédito ha sido un factor crítico en la bifurcación del régimen de acumulación, ya que ha tenido mayor disponibilidad para los grandes grupos que invirtieron en la reconversión, y más caro y escaso para los pequeños productores no reconvertidos (Rofman y Collado, 2005). Las opciones de estos últimos se han visto limitadas, principalmente, a diversos programas de financiamiento lanzados por gobiernos provinciales $\mathrm{u}$ órganos de gobernanza sectoriales -entre los que se destaca, por ejemplo, el Proyecto Integración de Pequeños Productores a la Cadena Vitivinícola (PROVIAR), auspiciado por la Corporación Vitivinícola Argentina (COVIAR)-.

Estado

Históricamente, el Estado ha tenido un rol muy activo en el desarrollo de la industria vitivinícola (Olguín, 2012); ha intervenido a través de la creación, modificación o abolición de marcos normativos, del establecimiento de entidades regulatorias públicas (Chazarreta, 2012:208) y de la constitución de corporaciones pertenecientes a los estados provinciales (como Bodegas y Viñedos Giol en Mendoza o la Corporación Agroeconómica Vitícola y Comercial -CAVIC- en San Juan). 
Sin embargo, a pesar de la larga historia de intervención estatal, durante el proceso de reconversión, que comenzó amparado por las políticas neoliberales de los noventa, los actores privados vinieron a ocupar un lugar importante. El nuevo modo de regulación global promovía un Estado menos interventor. Así, sometido a los imperativos de la desregulación, el Estado aspiró a eliminar toda legislación que interfiriera con la libertad de acción de los agentes económicos y redujo las atribuciones del INV a poco más que controles de calidad. En este sentido, la retracción del Estado tiene que ser explicada en relación con la transformación más general del modo de regulación global.

Como contrapartida, fueron los gobiernos provinciales los que tuvieron un rol más activo (RichardJorba, 2008). Si bien continuaron con algunas políticas del modelo tradicional (como la compra de vino o el establecimiento de cuotas para mosto), lo más destacable fue la nueva forma de articulación con actores del sector que desarrollaron, en el que sobresalen los que podrían ser descriptos como órganos de gobernanza sectorial -caracterizados por la presencia de actores privados (bodegas, comercializadores, productores vitícolas y sus respectivas organizaciones gremiales) y representantes de gobiernos provinciales o agencias estatales (Chazarreta, 2014). A partir de las recaudaciones provenientes del acuerdo Mendoza-San Juan -que estipuló mínimos de producción de mosto y una contribución obligatoria para las bodegas que no lo cumplieran- se crea el Fondo Vitivinícola, una entidad de derecho público no estatal con el mandato de promocionar el consumo (Bertranou, 2011).

Pero quizás el ejemplo más importante de esta nueva tendencia sea el Plan Estratégico Vitivinícola 2020 (PEVI). El principal objetivo del PEVI fue diagnosticar el estado de la industria y definir objetivos estratégicos a ser alcanzados por el sector para el año 2020. Este proceso involucró a representantes de organizaciones de productores de uva y vino, asociaciones de cooperativas, exportadores, universidades y organismos gubernamentales y público-privados especializados. Así, el sector se dio a sí mismo un plan y se lo presentó a los parlamentarios de las provincias vitivinícolas, quienes lo llevaron al congreso para su aprobación en 2003. Una de sus consecuencias más inmediatas fue la creación de COVIAR, cuyo principal objetivo es el de administrar y coordinar la implementación del PEVI 2020. La misma, ejemplo paradigmático de órgano de gobernanza sectorial, se encuentra integrada por entidades públicas y privadas: de los 17 miembros de su mesa de representantes 12 pertenecen a cámaras de negocios o productores, mientras que los otros cinco son representantes del sector público (INV, INTA, gobierno de Mendoza, gobierno de San Juan y un miembro rotativo de las demás provincias productoras).

Representación del producto

La representación dominante del producto dentro del régimen de acumulación basado en la cantidad era la del vino de mesa para consumo de masas, un producto que debía ser provisto en grandes cantidades para satisfacer la demanda de una población cuyo consumo per cápita parecía crecer ilimitadamente. El vino se representaba como un producto ordinario para consumo cotidiano y, como consecuencia, las expectativas en torno a su calidad no eran muy diferentes a las de, por ejemplo, el pan, ya que se reducía a ciertos mínimos de aceptabilidad.

En la industria construida en torno a dicha representación, la principal preocupación era garantizar la provisión. Dado que las expectativas de calidad se limitaban a mínimos, no era poco habitual escuchar hablar del "estiramiento" de vinos -la acción de agregar agua para aumentar stocks-. Si bien esta no era una práctica legal, la representación dominante hacía de la cantidad y la disponibilidad del producto un imperativo tan importante que la calidad se volvía negociable. Un claro ejemplo tuvo lugar durante el primer gobierno de Perón cuando, a causa de las políticas redistributivas de la época, se produjo un incremento en el consumo de más de 15 litros per cápita. Ante la escasez que sobrevino, el gobierno decidió intervenir. Entre las varias medidas tomadas hubo una de especial relevancia para la forma institucional que examinamos: el establecimiento de un contenido máximo de alcohol del 12 \% (Mateu, 2014:154). Según explica Marianetti (1965, p. 304), la nueva norma exigía reducir los niveles de alcohol, pero al no haber vinos con una graduación 
menor al $12 \%$, la medida implicó una aceptación tácita del estiramiento. Así, se volvió posible encontrar vinos con niveles entre el $8 \%$ y $9 \%$ (Mateu, 2014, p. 154).

Como se describió en la sección anterior, el sector se encuentra dominado actualmente por dos representaciones del producto, las cuales coexisten pero se diferencian claramente. A nivel técnico, estas diferentes representaciones, y su jerarquía, se operacionalizan a través de las regulaciones del INV. Esto se aprecia claramente en su resolución 12/2004, cuyo principal objetivo fue recategorizar los vinos para transparentar y homogeneizar los distintos niveles de calidad. Así, se definen dos tipos de productos: vino y varietales. Si bien cualquier tipo de vino debe cumplir con el mínimo de alcohol demandado por INV definido de acuerdo con las características de la cosecha de cada año y no por motivos socioeconómicos como en el pasado- se establecen criterios diferenciales para cada nivel de calidad: los vinos básicos deberán utilizar 122 kilos de uva para producir 100 litros, mientras que los varietales deberán utilizar por lo menos 130 kilos por cada 100 litros.

Asimismo, esta diferenciación entre los distintos vinos se acompaña de una clasificación de los tipos de uva. Con la creación de un sistema de indicaciones geográficas se vino a establecer una jerarquización a través de tres categorías: Indicación de Procedencia, por la que un vino puede producirse con cualquier tipo de uva, siempre y cuando el 80 \% provenga de dicha región; la Indicación Geográfica, en cambio, exige respetar la proporción de uvas por litro exigida para los varietales y sólo permite la utilización de uvas aptas para elaborar "vinos de calidad", y la Denominación de Origen Controlada restringe el número de variedades aceptables a aquellas definidas como aptas para elaborar "vinos de calidad superior". Esta resolución se acompaña de un anexo donde el INV ofrece un listado de los tipos de uva que pertenecen a cada nivel de calidad (ver resoluciones de INV: 32/2002; 8/2003; 18/2004; 22/2006; 7/2009 y 52/2012).

Inserción internacional

La producción y comercialización de vino de mesa apunta principalmente al mercado doméstico, y se exporta de manera esporádica de acuerdo con las oportunidades que pudieran emerger. El régimen de acumulación reconvertido, en cambio, siempre ha considerado a las exportaciones como el destino principal de sus productos. La importancia del mercado externo puede apreciarse claramente en el PEVI, ya que uno de sus principales objetivos estratégicos es posicionar a los vinos finos argentinos en los "mercados del norte".

Sin embargo, las posibilidades de exportar están fuertemente determinadas por el modo global de regulación. El período 2002-2009 atestiguó un boom en las exportaciones que fue impulsado por el tipo de cambio competitivo que adoptó el gobierno nacional. No obstante, la situación comenzó a cambiar, especialmente a partir de 2013 (ver Figura 3). Esto fue una consecuencia de la convergencia entre una muy baja movilidad del tipo de cambio y el constante y alto ritmo de crecimiento de la inflación, lo que provocó un alza en los costos de producción. Como el mercado internacional es sensible a los cambios de precio, los productores no pudieron ajustarlos de acuerdo a sus costos de producción, por lo que vieron reducidos sus márgenes de ganancia y/o debieron destinar parte de su producción al mercado interno. Los vinos premium y ultrapremium, en cambio, han continuado siendo comercializados porque ofrecen mayores márgenes de ganancia.

\section{ConCLUSIÓN}

Desde comienzos de los noventa la industria vitivinícola ha experimentado importantes transformaciones: tras sufrir la crisis de regulación de su modelo histórico ha debido producir cambios estructurales para retomar la senda de la acumulación sectorial. Este fenómeno ha sido explicado aquí en términos regulacionistas como el surgimiento de una dualidad en el régimen de acumulación y la estructuración de un modo de regulación compatible. En esta conclusión me gustaría destacar las contribuciones de este análisis tanto a los trabajos que han examinado al proceso de transformación de la industria vitivinícola como a la literatura regulacionista. 
En la introducción se criticó a la noción de una "reconversión inconclusa” por sus tintes teleológicos, ya que dicha conceptualización implica suponer que un proceso de evolución ha sido interrumpido. Sin embargo, el análisis más estructural que permite la TR demuestra que el proceso de reconversión no puede extenderse a la industria como un todo, sino que se restringe a un régimen de acumulación singular. Asumir que el régimen de acumulación basado en la calidad aún no terminó de reemplazar al régimen de acumulación basado en la cantidad supone dar por hecho que la todavía importante demanda de vino de mesa y el alto número de productores cuya sustentabilidad económica y social depende del modelo tradicional pueden ser fácilmente sustituidos o "reconvertidos" (Heredia y Poblete, 2013).

Conceptualizar a la estructura actual del sector, en cambio, como una dualidad de regímenes de acumulación permite evitar las suposiciones sobre la inevitabilidad de la hegemonía absoluta de la reconversión (Chazarreta, 2013) y describir la coexistencia de dos modelos de acumulación. Así, es más preciso afirmar que la acumulación y estabilidad del sector han podido ser restablecidas gracias al desarrollo de dicha dualidad y no pesar de la misma. Ahora bien, esto no supone negar el carácter jerárquico y desigual propio no sólo de las relaciones entre los distintos actores de la industria, sino también de las relaciones entre ambos regímenes de acumulación: el basado en la calidad ha demostrado un mayor dinamismo y se ha expandido -en términos de volumen y valor- a expensas del basado en la cantidad, que en su contracción ha experimentado también una tendencia hacia la concentración, lo que pone en una situación más precaria a los pequeños productores vitícolas y vinícolas que lo integran (Staricco, 2015, pp. 166-171; Staricco y Ponte, 2015, p. 71).

El repaso de la historia reciente de la industria vitivinícola ha dejado en evidencia que su estabilidad, desarrollo y crisis han demostrado patrones cambiantes en las relaciones entre el nivel sectorial y el macro. Así, a fines de los ochenta ambos entran en crisis y reemergen transformados en los noventa, pero a principios del siglo XXI el modo de desarrollo enfrenta una nueva transformación que sólo viene a potenciar el camino emprendido por el sector vitivinícola años atrás. A la luz de un marco conceptual regulacionista, este hecho viene a respaldar el supuesto inicial de acuerdo con el cual es erróneo entender la lógica de un sector, tanto desde una perspectiva que estresa su relación funcional con el nivel global, como desde aquella otra en la que se sobredimensiona la autonomía del sector. Si seguimos a Boyer (1990b), y entendemos al régimen de acumulación y modo de regulación sectorial como una forma específica que adquieren el régimen de acumulación y el modo de regulación global dentro de los límites de una industria dada, es posible arribar a la conclusión de que un sector no es nunca totalmente autónomo. Sin embargo, la incidencia del nivel global sobre el sectorial no puede ser presupuesta y debe ser analizada empíricamente en sus propias condiciones históricas, ya que se caracteriza por una relación de no necesariedad que va a contracorriente de las explicaciones funcionalistas.

\section{REFERENCIAS}

Acosta, G., y Vitale, J. (2012). Aportes al desarrollo territorial para el fortalecimiento de la articulación institucional y la agricultura familiar: el caso del centro de desarrollo vitícola en la zona norte de la provincia de Mendoza. $X V$ Jornadas Nacionales de Extensión Rural y VII del Mercosur, Potrero de los Funes, 6-8 de octubre.

Altschuler, B. (2012). Fronteras sociales y asimetrías en la vitivinicultura mendocina actual. Cuadernos de desarrollo rural, 9(68), 151-175.

Artopoulos, A., Friel, D., y Hallak, J. (2010). Challenges of Exporting Differentiated Products to Developed Countries: The Case of SME-Dominated Sectors in a Semi-Industrialized Country. IDB Working Paper Series: IDB-WP-166.

Azpiazu, D., y Basualdo, E. (2001). El complejo vitivinicola argentino en los noventa: potencialidades y restricciones. Buenos Aires: CEPAL-ONU. 
Azpiazu, D., y Basualdo, E. (2003). Estudios sectoriales. Componente: industria vitivinícola. Buenos Aires: CEPALONU.

Bartoli, P. y Boulet, D. (1990). Conditions d'une approche en termes de régulation sectorielle : Le cas de la sphère viticole. Cahiers d'économie et sociologie, 17, 7-38.

Bertranou, J. (2011). Estado y agencias público-privadas en la promoción del desarrollo productivo en la Provincia de Mendoza. Documentos y aportes en administración pública y gestión estatal, 17, 7-40.

Bocco, A., Alturria, L., Ruiz, A. M., Salvarredi, G., Vila, H., y Oliva, J. (2007). La trama vitivinícola en la provincia de Mendoza. En M. Delfini, et al (Ed.), Innovación y empleo en tramas productivas de Argentina (pp. 43-92). Buenos Aires: Prometeo Libros.

Bocco, A., y Dubbini, D. (2007). Regulaciones laborales y calidad de empleo en la trama vitivinícola de Mendoza. $8^{\circ}$ Congreso Nacional de Estudios del Trabajo, Montevideo.

Boyer, R. (1990a). The Regulation School: A Critical Introduction. Nueva York : Columbia University Press.

Boyer, R. (1990b). Les problématiques de la régulation face aux spécificités sectorielles : Perspectives ouvertes par la thèse de Pierre Bartoli et Daniel Boulet, Cabiers d'économie et sociologie, 17, 39-76.

Boyer, R. y Saillard, Y. (2002). Un précis de la régulation. En R. Boyer y Y. Saillard (Ed.), Théorie de la régulation : L'état des savoirs (pp. 58-68). París: Éditions La Découvert.

Chazarreta, A. S. (2012). Los impactos de la reestructuración económica en la clase capitalista: la recomposición de la burguesía vitivinicola en la Provincia de Mendoza (1990-2011) (Tesis doctoral), Universidad Nacional General Sarmiento, Buenos Aires, Argentina.

Chazarreta, A. S. (2013). Capital extranjero y agroindustria. Notas para una discusión sobre los cambios en la burguesía vitivinícola de Argentina a partir de la década del '90. Mundo Agrario, 13(26)

Chazarreta, A. S. (2014). Los cambios en la organización gremial de la burguesía vitivinícola de la provincia de Mendoza, Argentina (1990-2011). Pampa, 10, 55-85.

Costa, A. (1972). Evolución técnica de las plantas de fraccionamiento argentinas. Anuario Vitivinícola 1972.

Fabio, J. (2010). Regulación social de la transitoriedad. El mercado de trabajo en la producción de uvas en Mendoza, Argentina. Cuadernos de Desarrollo Rural, 7(64), 33-57.

Heredia, M. (2015). Globalización y clases altas en el auge del vino argentino. Trabajo y sociedad, 25, 267-284.

Heredia, M., y Poblete, L. (2013). La estratificación socio-laboral en un caso de globalización exitosa: La vitivinicultura mendocina (1995-2011). Mundo Agrario, 14(27).

Hernández Duarte, R. (2014). Transformación Productiva y Relaciones Agroindustriales en la Cadena Vitivinícola de la Provincia de Mendoza. Pilquen, 14(1), 1-20.

Lacroix, A., Mollard, A., y Bel, F. (1994). L'approche sectorielle de la régulation : une problématique á partir de l'agriculture. En G. Allaire y R. Boyer (Ed.), La grande transformation de l'agriculture (pp. 259-291). Paris: INRA Editions.

Lipietz, A. (1983). The Enchanted World: Inflation, Credit and the World Crisis. Londres: Verso.

Lipietz, A. (1987). Mirages and Miracles: The Crises of Global Fordism. Londres: Verso.

Lipietz, A. (1988). Reflections on a Tale: The Marxist Foundations of Concepts of Regulation and Accumulation. Studies in Political Economy, 26, 7-36.

Maclaine Pont, P. (2011). Who Grows the Grapes? The Changing Relationship of Quality in Argentine Wine Production. Journal of Wine Research, 22(1), 1-17.

Maclaine Pont, P., \& Thomas, H. (2012). The Sociotechnical Alliance of Argentine Quality Wine: How Mendoza's Viticulture Functions Between the Local and the Global. Science, Technology \& Human Values, 37(6), 627-652.

Marianetti, B. (1965). El racimo y su aventura: la cuestión vitivinicola. Buenos Aires: Platina.

Martín, F. (2009). Las transformaciones recientes en la agricultura de oasis en Mendoza, Argentina. Una aproximación al caso de la reestructuración vitivinicola desde la economia política de la agricultura (Tesis de maestría), Facultad Latinoamericana de Ciencias Sociales, Buenos Aires, Argentina. 
Mateu, A. M. (2007). El modelo centenario de la vitivinicultura mendocina: génesis, desarrollo y crisis (1870-1980). En M. Delfini et al (Ed.), Innovación y empleo en tramas productivas de Argentina (pp.19-42). Buenos Aires: Prometeo Libros.

Mateu, A. M. (2008). La vitivinicultura mendocina entre 1870 y 1920. En A. M. Mateu y S. Stein (Ed.), El vino y sus revoluciones: una antología histórica sobre el desarrollo de la industria vitivinicola argentina (pp.15-30). Mendoza: EDIUNC.

Mateu, A. M. (2014). Las posturas oscilantes de una centenaria corporación vitivinícola frente a la regulación de la industria, Mendoza, 1930-1955. América Latina en la Historia Económica: Revista de Investigación, 21(1), 134-173.

Mateu, A. M. y Stein, S. (Eds.) (2008). El vino y sus revoluciones: una antologi\#a histo\#rica sobre el desarrollo de la industria vitivini\#cola argentina. Mendoza: EDIUNC.

Miranda, O. (2014). Cambios estructurales en la vitivinicultura argentina (presentación de Power point). Recuperado de: http://inta.gob.ar/documentos/cambios-estructurales-en-la-vitivinicultura-argentina/at_multi_download /file/INTA-\%20Cambios_estructurales.pdf. Último acceso: 20 de noviembre de 2014.

Moscheni, M., y Carrizo, C. (2015). Las encrucijadas de los trabajadores vitivinícolas: sindicatos y capital. Trabajo y Sociedad, 25, 329-351.

Neffa, J. C. (1998). Modos de regulación, regimenes de acumulación y sus crisis en Argentina (1880-1996): una contribución a su estudio desde la teoría de la regulación. Buenos Aires: Eudeba.

Neffa, J. C., y Panigo, D. (2010). Modelos productivos y sus impactos sobre la relación salarial. reflexiones a partir del caso argentino. En E. De la Garza Toledo y J. C. Neffa (Eds.), Trabajo y modelos productivos en Ame\#rica Latina: Argentina, Brasil, Colombia, Me\#xico y Venezuela luego de las crisis del modo de desarrollo neoliberal (pp. 216-374). Buenos Aires: CLACSO.

Neffa, J. C. (2006). Evolución conceptual de la teoría de la regulación. En E. De la Garza Toledo (Ed.), Teorías sociales y estudios del trabajo: Nuevos enfoques (pp. 183-206). Ciudad de México: Anthropos Editorial.

Neiman, G., y Bocco, A. (2001). Mercados de calidad y trabajo. El caso de la vitivinicultura argentina. $5^{\circ}$ Congreso Nacional de Estudios del Trabajo.

Neiman, G., y Quaranta, G. (2016). Intermediación, empresas y mercados de trabajo en las producciones de vid de la región de Cuyo, Argentina. Eutopia, 9, 83-100.

OIV (2009). Vine and Wine Outlook 2008-2009. OIV Statistical Publications. Recuperado de: http://www.oiv.int/o iv/files/OIVStatistiques2008-2009.pdf. Último acceso: 20 de marzo de 2014.

OIV (2016). State of the vitiviniculture world market. Recuperado de: http://www.oiv.int/public/medias/4710/oivnoteconjmars2016-en.pdf. Último acceso: 19 de enero de 2017.

Olguín, P. (2012). Estado, empresas y regulación. La experiencia de las entidades reguladoras del mercado vitivinícola de Mendoza (Argentina). Revista de Historia Industrial, 49(21), 1014-1943.

Poblete, L. (2008). De la pauvreté stable à l'instabilité dans la pauvreté. Études rurales, 181(1), 61-74.

Poblete, L. (2011). El colectivo como vía de acceso al trabajo. El caso de los trabajadores vitícolas de Mendoza, Argentina (1995-2010). Cultura e Sociedade, 14(1), 41-51.

Poblete, L. (2012). De trabajadores inamovibles a trabajadores móviles. El caso de los contratistas de una región vitícola de Mendoza, Argentina (1995-2010). Cuadernos de Relaciones Laborales, 30(2), 519-539.

Richard-Jorba, R. (2008). Los empresarios y la construcción de la vitivinicultura capitalista en la provincia de Mendoza (Argentina), 1850-2006. Scripta Nova, 12, 256-280.

Rofman, A., y Collado, P. (2005). El impacto de la crisis de los años 2001-2002 sobre el circuito agroindustrial vitivinícola y los agentes económicos que lo integran. IV Jornadas Interdisciplinarias de Estudios Agrarios y Agroindustriales, Buenos Aires.

Stein, S. (2008). La dinámica de una industria: fracasos y éxitos en la lucha por vinos de calidad. En A. M. Mateu y S. Stein (Eds.), El vino y sus revoluciones: una antología histórica sobre el desarrollo de la industria vitivinícola argentina (pp. 31-48). Mendoza: EDIUNC. 
Staricco, J. I. (2015). Towards a Fair Global Economic Regime? A Critical Assessment of Fair Trade through the Examination of the Argentinean Wine Industry (Tesis doctoral), Copenhagen Business School, Copenhague, Dinamarca.

Staricco, J. I. (2016). Towards a fair agri-food regime? A regulationist reading of the Fairtrade system. Revue de la régulation 20(2), pp. 1-21 (versión pdf). Recuperado de: https://regulation.revues.org/12148. Último acceso: 14-de febrero de 2017.

Staricco, J. I., \& Ponte, S. (2015). Quality regimes in agro-food industries: A regulation theory reading of Fair Trade wine in Argentina. Journal of Rural Studies, 38, 65-76.

Tacchinni, J. (2008). Mercado vitivinícola. En A. M. Mateu y S. Stein (Eds.), El vino y sus revoluciones: una antologi\#\#a histo\#rica sobre el desarrollo de la industria vitivini\#cola argentina (pp. 355-9). Mendoza : EDIUNC.

Touzard, J. M. (1994). Régulation sectorielle, dynamique régionale et transformation d'un système productif localisé : exemple de la viniculture languedocienne. En G. Allaire y R. Boyer (Eds.), La grande transformation de l’agriculture (pp. 293-322). París: INRA Editions.

\section{Notas}

1 En la literatura regulacionista se suele utilizar el término global para hacer referencia al nivel macro por oposición al nivel sectorial. En este contexto no debe confundirse con una escala inter- o trasnacional.

2 El análisis empírico cubierto en este artículo se extiende hasta 2015, ya que considero que todavía es demasiado pronto para determinar si los cambios llevados adelante por el gobierno de Macri constituyen los primeros pasos hacia una transición en el modo de desarrollo o no afectarán los pilares fundamentales del modo de desarrollo anterior. 